\title{
Masculinidades e Violências: Narrativas de Vida de Jovens em Conflito com a Lei
}

\author{
Masculinities and Violence: Life narratives of Youths in Conflict with the Law
}

\author{
Caio Andrêo Silva' (orcid.org/ 0000-0001-7293-5866) \\ Leonardo Lemos de Souza² (orcid.org/0000-0002-3331-1847)
}

\begin{abstract}
Resumo
O presente artigo tem por objetivo descrever os processos de subjetivação de masculinidades em interface com as violências, tendo por base narrativas de vida de quatro jovens com idades entre 16 e 18 anos, que cumpriram medidas socioeducativas numa instituição socioassistencial. As análises foram feitas com base nas perspectivas sobre discurso e enunciado em Bakhtin e Foucault, destacando suas produções como fontes de discursos capazes de desvelar processos de subjetivação, bem como os estudos sobre masculinidades. A partir das análises, foram produzidos três eixos temáticos: relação entre os bailes funks com masculinidades, poder e violência; violências familiares e estruturais na subjetivação juvenil; e relações de violências de gênero e masculinidades presentes nas relações afetivas. As discussões apontam problematizações oriundas Psicologia que promovem rompimentos diante da naturalização das masculinidades relacionadas à violência e possíveis contribuições de perspectivas críticas que permitam sua pluralização e a (re)invenção das possibilidades de existência dos jovens.
\end{abstract}

Palavras-chave: Masculinidades. Psicologia. Juventude. Violência.

\begin{abstract}
This article aims to describe the processes of subjectivation of masculinities in interface with violence, based on the perspectives on narratives of four young people between the ages of 16 and 18, who fulfilled socio - educational measures within a socio - welfare institution. The analyzes were made based on the perspectives about the speech and statement in Bakhtin and Foucault, highlighting their productions as sources of discourses capable of revealing processes of subjectivation, as well as the studies about masculinities. From the analysis, three thematic axes were produced: relationship between the funk dances with masculinity, power and violence; family and structural violence in youth subjectivation; relations of gender violence and masculinities present in affective relationships. The discussions point out problematizations arising from Psychology that promote disruptions due to the naturalization
\end{abstract}

\footnotetext{
1 Centro Universitário das Faculdades Integradas de Ourinhos, Ourinhos, Brasil. E-mail: caioandreo@gmail.com.

2 Universidade Estadual Paulista, Assis, Brasil. E-mail: leonardo.lemos@unesp.br
} 
of masculinities related to violence and possible contributions from critical perspectives that allow their pluralization and the (re)invention of the possibilities of existence of the young people.

Keywords: Masculinities. Psychology. Youth. Violence. 


\section{Introdução}

A exposição dada à juventude do sexo masculino, quando diretamente envolvido com as violências, seja na condição de vítimas, seja na de autores, merece grande atenção de estudos e pesquisas em diversos campos do saber. Considerando os avanços em termos de leis e diretrizes, como o Estatuto da Criança e do Adolescente (1990), o Estatuto da Juventude (2013) e referenciais teóricos da Psicologia e mesmo de outras áreas do saber (Dayrell, 2003; Rogoff, 2005; Pais, 1990; Coimbra, Bocco \& Nascimento, 2005) que atuaram na mudança de paradigmas em relação à juventude, ainda constam discursos e práticas que retratam a visão do jovem tomado por uma noção de incompletude, um vir-a-ser que ainda não é (adulto) e necessita ser corrigido e lapidado para que não se torne um problema para a sociedade e o Estado, seja na sua condição de adulto ou mesmo de jovem.

Do mesmo modo, diversas instâncias colocam em cena a relação entre juventude, pobreza e violência permeada de visões estigmatizantes que designam o jovem que comete um ato violento como menor delinquente, criminoso, marginal, entre outras características depreciativas (Adorno, Bordini \& Lima, 1999; Lima, 2009; Volpi, 2010).

No cerne dessa problemática, caberia a seguinte questão: por que o gênero masculino é mais frequentemente associado a tais atos? Muitos autores apontam para essa aproximação das masculinidades com a violência (Nascimento, Segundo \& Barker, 2009; Beiras \& Nascimento, 2017; Nascimento \& Aguayo,
2016; Grossi, 2004; Oliveira, 2005; Souza, 2005; Welzer-lang, 2004) - e levantamentos recentes ${ }^{3}$ ainda mostram jovens do sexo masculino diretamente envolvidos com atos violentos, em que há a necessidade de compreender como é construída e constituída essa relação e se há, de fato, uma correlação baseada nas questões de gênero e sexualidade. A naturalização desse interjogo mostra, em muitos casos, que ainda temos de avançar nessas discussões e problematizar os fatores que intermedeiam a questão.

Ademais, partindo de uma perspectiva pós-estruturalista, a compreensão das produções discursivas e subjetivas de muitos jovens, numa leitura de gênero, é necessária para que se possa pensar numa Psicologia mais próxima com a perspectiva queer, de modo a desvelar como se constituem essas relações e suscitar novas modalidades de ser homem.

Pretende-se no presente artigo descrever os processos de subjetivação das masculinidades em interface com a violência de jovens que cumpriram ou estavam em cumprimento de medidas socioeducativas em regime meio aberto e, assim, apontar alguns elementos que podem indicar maior ampliação acerca dessa temática.

3

O último Levantamento Anual do Sistema Nacional de Atendimento Socioeducativo - Sinase (2016) mostra a predominância de $96 \%$ dos jovens do sexo masculino em cumprimento de medidas socioeducativas em regime meio fechado (internação e semiliberdade). 
Juventudes, Masculinidades e Violências: da Naturalização da Masculinidade Juvenil Violenta à Desconstrução e Multiplicidades

Durante muito tempo, os jovens sofreram com diversas formas de violências, de modo que não houve a promoção de suas emancipações como sujeitos de direito, permitindo-se, assim, o uso de práticas repressivas e discriminatórias (Volpi, 2010). Isso pode ser evidenciado recorrendo-se a uma história mais recente, a partir dos primeiros conjuntos de leis destinados à infância e à juventude, o Código de Menores de 1927, que, segundo apurou Marcílio (2006), se pautou no controle de crianças e jovens abandonados e delinquentes. Ainda nesse período, o Estado ficou restrito a controlá-los e puni-los, situação que se modificou apenas na década de 1960, quando o próprio Estado se tornou o grande interventor e responsável pela assistência e proteção dos jovens, seguido da criação da Fundação do Bem-Estar do Menor (Funabem), em 1964, e da elaboração do Estatuto do Menor, em 1979. A partir do aumento da pobreza urbana e da crescente progressão da violência nas cidades, foram promovidas inúmeras reações organizadas por diversos segmentos sociais, sobretudo na década de 1980, que visaram lutar pelos direitos de crianças e jovens, os quais eram muitas vezes violados pela polícia ou pelas Febems (Marcílio, 2006).

Somente a partir da criação do Estatuto da Criança e do Adolescente, em 1990, entrou em ação a Doutrina da Proteção Integral, que, mais do que uma lei de garantia de direitos, passa a ser uma lei civilizatória, assegurando para aqueles que estiverem em conflito com a lei ampla defesa, processo legal e as demais garantias constitucionais. Nessa nova doutrina, crianças e jovens passam a ser vistos como sujeitos em processo de formação, o que lhes abre espaço para o pleno exercício da cidadania.

Seguindo essa perspectiva, pretende-se tomar os jovens como operadores na diferença, criadores e inventores de mecanismos que arquitetam outros espaços que escapam dessa lógica normativa. Nesse sentido, adotamos a preferência pelos termos "jovem" e "juventude", em vez de "adolescente" e "adolescência", seguindo a sugestão das autoras Fernanda Bocco, Cecília Coimbra e Maria Lívia do Nascimento (2005). De modo similar, esses termos indicam, conforme esclarecem as autoras, a não referência a uma faixa etária específica nem a uma série de comportamentos que são reconhecidos como exclusivos dela, sugerindo, então, pensar em identidade adolescente, adotar "intensidade juvenil", destacando as forças que a constituem e perpassam.

De modo consoante, Rogoff (2005) afirma que a juventude se configura como uma invenção cultural, portanto não natural, em contextos culturais específicos, e que por um longo período foi tomada como um tempo de transição entre a infância e a vida adulta. O jovem tinha mais responsabilidades do que a criança e menos do que o adulto, sendo esses últimos seus supervisores. A autora ainda coloca que essas responsabilidades adquiridas em casa eram esquecidas no ambiente escolar, que o tratava como criança. 
Embora a juventude seja vista em muitas comunidades como uma época que não envolve necessariamente conflitos, em algumas ela é considerada um período de comportamentos rebeldes e crises emocionais permeadas por atitudes autocentradas. Tal desarmonia nesse momento, segundo Rogoff (2005), pode ser resultado da segregação sofrida pelos jovens quanto a seus papéis produtivos na sociedade, os quais estariam prontos para exercer, mas que são adiados, na maioria dos casos, até que atinjam a vida adulta.

Essa concepção se mostra relevante, na medida em que os desvios às normas, que individualizam e interiorizam questões sociais, também provocam a criminalização de muitos jovens, como os que são protagonistas neste estudo. É contra essas capturas e imposições que lutamos, pois como bem lembra Bocco, Coimbra e Nascimento (2005), a infração é apenas uma linha entre tantas outras que as compõem, assim como a violência. Sendo assim, não cabe aqui apenas tomar esses jovens como infratores, e sim criar outras vias de relação com suas vidas.

Com isso, a violência, tratada nesta discussão, se apresenta como um componente subjetivo e é produzida pelo convívio social, envolvendo elementos biopsicossociais. Desse modo, ela deve ser analisada também pela sua especificidade histórica (Michaud, 1989).

O termo violências (Michaud, 1989) remete à pluralidade de significados (alguns deles apresentados anteriormente) e tem como condição principal o uso de forças que pode acarretar em relações de poder, no que Chauí (1998) denominou de relação "mando- obediência" ou superior-inferior, remetendo àquele que comete um ato violento e não reconhece o outro como sujeito, em toda a sua complexidade, coisificando-o. Tais relações hierarquizadas podem ser vistas nas próprias relações familiares, amorosas, no trabalho e nas relações institucionais.

Há uma produção discursiva que é investida pelo desejo e que, segundo Foucault (2006), se acredita carregada de terríveis poderes que constituirão verdades sobre o ideal masculino, a uma série de características que os verdadeiros homens devem alcançar, muitas vezes baseado na força e na agressividade. Essa produção atinge diretamente os discursos dos jovens que são subjetivados por essa lógica da masculinidade em relação à violência, que os capturam e impossibilitam a criação de outras vias para suas vidas.

Foucault (2006) afirma que essa produção discursiva e os aparatos do poder e saber terão por função definir um determinado modo de existência, que aproximando com o campo das masculinidades encontrará o seu limite nesse próprio ideal masculino, que é fortemente almejado por muitos homens, de modo a conjurar a manutenção de seus domínios sobre as mulheres e outras expressões de gênero.

Os estudos sobre os homens e as masculinidades (Welzer-lang, 2001，2004; Connell, 1995, 2000, 2013; Boris, 2014; Kimmel, 2001, Seidler, 2000, 2006; Lyra, Medrado, 2008) se configuram como uma via nos estudos sobre gênero e sexualidade e envolvem uma série de discursos, conceitos e normas que a todo o momento perpassam a subjetivação de novas 
configurações masculinas. Torna-se necessária a compreensão histórica dessas construções e como elas se configuram na contemporaneidade, em conjunto com outros elementos como raça, idade, classe social e regiões.

De modo geral, as masculinidades integram as discussões sobre o que é ser homem na contemporaneidade, as quais buscam compreender os seus processos de subjetivação ao longo da história. No que se refere aos jovens autores de infração, que fazem parte desta discussão, há que se questionar se a violência se constitui como modelo de virilidade da sociedade patriarcal ou se vincula a outras construções relacionadas a práticas sociais cotidianas de suas vidas.

As masculinidades como campo de estudos exigem que retomemos a perspectiva relacional dos estudos de gênero. Desse modo, estudar as produções de masculinidades e seus atravessamentos com a masculinidade hegemônica (Connell, 2013) - virilidade pautada na força, agressividade, liderança, violência, poder e o predomínio da heteronormatividade é, de certo modo, trazê-la como produções discursivas e de análise das lógicas binárias das relações entre homens e mulheres e as decorrentes violências engendradas.

Do mesmo modo, trazer o marcador etário da juventude na produção de masculinidades é inserir a discussão desde leituras interseccionais, destacando a temporalidade da vida na experiência com os gêneros e a violência, acompanhando o processo de constituição de valores, normas e sentidos sobre si mesmo e o mundo.
Para isso, os procedimentos de exclusão, controle e delimitação dos discursos (Foucault, 2006) se efetivam sobre subjetividades masculinas que passam a naturalizar essa relação entre juventude e violência, pois a própria juventude masculina passa a ser perigosa, delinquente, desviante e mais suscetível a cometer um ato violento, impedindo a manifestação de devires, multiplicidades e diferenças que as constituem (Bocco; Coimbra; Nascimento, 2005).

\section{Narrativas e Produção de Subjetividades: as} Histórias de Vida dos Jovens

Para que seja possível investigar as masculinidades e suas relações com a violência em jovens do gênero masculino, foi indispensável tomarmos o conceito de subjetividade como ponto de partida da pesquisa. Sendo assim, ela se configura como o eixo central no processo investigativo dos referenciais adotados, que a entende como algo que se constitui no diálogo pesquisadorpesquisado durante todo o percurso da pesquisa e as dimensões socioculturais envolvidas.

Para Bakhtin (2006), a constituição subjetiva passa pela dialogia que será instaurada no sujeito a partir de sua relação com o outro, também como um ente histórico, social e cultural, para que haja a produção de subjetividade e a organização das experiências. Essa produção e organização apenas serão possíveis pela linguagem, pensada como voz social. Trata-se também de evocar outros conceitos, o de enunciação e discurso na produção narrativa. Bakhtin (2006) nos sugere 
que o discurso se materializa na interação concreta de enunciados de determinados falantes. O sujeito do discurso, portanto, se constitui na relação com a alteridade e, dessa forma, as enunciações produzidas estão nos sentidos dados ao discurso. $\mathrm{O}$ discurso se constitui pelos valores e conhecimentos do sujeito e se expressam pela interdependência entre ele e o enunciado. Essa dimensão da produção discursiva nos remete ainda à inseparabilidade entre o que é dito e como é dito, ou seja, pelos elementos linguísticos e também não verbais da situação, que podem ser projetados a partir de memórias.

Já para Foucault (2006), essa produção pode ser vista como externa, ao sujeito, ou seja, ela se consuma por fora e por meio dos discursos - saberes - que moldarão essa subjetividade de acordo com suas conformidades. Para o autor, o enunciado presente na narrativa de uma teoria ou de práticas, por exemplo, materializam uma ordem que tem uma função. $\mathrm{O}$ enunciado tem implicações sobre como são inseridos numa lógica ordenativa as vivências, os pensamentos, as definições de palavras, objetos, documentos, imagens etc. Como efeitos de saberes sobre a vida. A memória aqui é a priori e produz efeitos na produção dos enunciados num domínio de coexistência.

Apesar das diferenciações epistêmicas e modos de tratar o conceito de discurso e enunciado desses autores, podemos afirmar a presença de indícios de que os processos de subjetivação passam pelas produções discursivas, a partir de diferentes dimensionalidades de análise - seja nas dimensões concretas das interações sociais entre indivíduos, para Bakhtin (2006), seja pelos efeitos de saber produzidos pela sociedade num determinado campo epistemológico, como em Foucault (2006).

Para ambos, o discurso é heterogêneo, como um conjunto de enunciados que são dispersos em vozes de saberes. Se para Bakhtin o discurso sempre tem um dono, ele não é nada sem o outro (alteridade no processo dialógico). Assim, não se trata de um sujeito refratário, indiviso. Já para Foucault, os signos existem, pois há alguém para enunciá-lo, mas esse autor nunca é idêntico ao sujeito do enunciado.

Desse modo, a produção discursiva pode ser pensada nessas aproximações desses dois autores como algo que se enreda de maneira heterogênea em temas, saberes, valores, afetos e outros elementos que produzem práticas e efeitos de poder.

Pensamos que são planos diferentes de descrição e análise sobre a produção discursiva, mas que trazem contribuições interessantes para a investigação de narrativa de vida que são perpassadas pelas questões concretas do processo dialógico da entrevista de investigação, nos saberes que se remetem a processos epistemológicos e históricos sobre o sujeito, a violência, a juventude e adolescência, os afetos, a sexualidades, as masculinidades, a vida.

Uma das funções da narrativa é a de subjetivar o mundo e abrir espaço para o hipotético, isto é, para perspectivas possíveis capazes de constituir a vida genuína da mente interpretativa. Para Bruner (1991), as narrativas representam um modo específico de construção e constituição da realidade, pois seu 
conhecimento depende do contexto cultural em que está inserido. Nesse sentido, seu uso na Psicologia se mostra relevante, na medida em que sua particular abertura e plasticidade permitem maior qualidade na criação de outras formas de constituir realidades, significados e discursos que vão possibilitar a expressão de mentes com maiores capacidades interpretativas.

Entre as diversas espécies narrativas, utilizamos as narrativas autobiográficas, que têm a finalidade de contar a história de um indivíduo e seu caráter social (Germano \& Serpa, 2008). Nesse sentido, a biografia se caracteriza por um discurso narrado pelo sujeito autor e protagonista, que instaura um campo de renegociação e reinvenção identitária.

Carvalho (2003) esclarece que os métodos biográficos operam numa espécie de interjogo entre a privacidade do sujeito que narra e o espaço sócio-histórico e cultural de sua existência, fazendo com que seja promovida uma articulação narrativa no relato autobiográfico. Em outras palavras, as autobiografias serão colocadas em continuidade, tendo como base uma história social construída e compartilhada, na qual se inserem continuidades individuais conduzidas pelo próprio sujeito.

A presente pesquisa se configurou como um estudo de múltiplas vozes (Bakhtin, 1997) de caráter qualitativo. Sua realização ocorreu em uma instituição socioassistencial situada num município do interior do Estado de São Paulo, em que entrevistamos quatro jovens do sexo masculino com idades entre 16 e 21 anos, em cumprimento de medidas socioeducativas ou egressos que mantinham vínculos com a instituição. A seleção dos jovens foi realizada pela instituição e ocorreu por meio de convites pela equipe técnica a todos os acompanhados e alguns egressos que ainda tinham vínculos e compareciam ao equipamento. Vale ressaltar que um número maior de entrevistas não foi possível devido ao pequeno porte do município, que contava com poucos jovens em cumprimento de medidas socioeducativas e egressos que mantinham vínculos com a instituição, além do fato de que alguns relatos foram descartados devido ao pouco tempo de gravação e não apresentaram elementos suficientes que possibilitassem suas descrições e análises, bem como algumas desistências ocorridas durante o processo.

Depois da seleção, os jovens foram convidados a produzir suas narrativas autobiográficas de forma individual, de modo que se sentissem mais à vontade, dispondo do tempo que achassem necessário. As questões pertinentes emergiram a partir das narrativas, também como forma de estimular o prosseguimento nos relatos sobre suas histórias de vida; segundo aponta Gibbs (2009), como a cronologia, atores sociais presentes, momentos fundamentais ou eventos decisivos, influências e planejamentos. $\mathrm{O}$ registro das entrevistas narrativas foi realizado com gravação de voz e posterior transcrição pelo pesquisador responsável. ${ }^{4}$

Os quatro jovens que se disponibilizaram a compor as narrativas que

\footnotetext{
4 A presente pesquisa foi aprovada pelo Comitê de Ética em pesquisa da Faculdade de Ciências e Letras de Assis-SP, com Parecer n. 535.788 e CAAE $\mathrm{n}^{\circ}$ 17441513.1.0000.5401, em 13 de fevereiro de 2014.
} 
foram contempladas nesta discussão tiveram a modificação de seus nomes e demais informações que pudessem identificá-los, de forma a garantir o anonimato.

A análise das narrativas autobiográficas tomará como fonte de dados as entrevistas realizadas com os jovens e será feita adotando a perspectiva "construções de vida" (Bude, 1984 apud Flick, 2009), que partirá do princípio de tomar as narrativas como construções subjetivas e sociais produzidas pelo participante em diálogo com o entrevistador. Houve uma organização dos relatos dos jovens com base no tempo narrativo, metas, interações, ações, motivos, circunstâncias e o desfecho até o cumprimento das medidas (Lyra \& Ribeiro, 2008; Bakhtin, 1997).

Para este artigo, objetivou-se a apresentação do destaque de eixos temáticos decorrentes desses relatos, contemplando algumas características presentes nos relatos autobiográficos, ${ }^{5}$ segundo aponta Gibbs (2009), como a cronologia, atores sociais presentes, momentos fundamentais ou eventos decisivos, influências e planejamentos. Com a escolha dos trechos selecionados dos relatos dos jovens, pretende-se buscar os entrelaçamentos e sentidos das masculinidades e as violências em suas vidas e o significado atribuído a esses sentidos.

Os eixos temáticos contemplaram três discussões: relação entre os bailes funks com masculinidades, poder e violência; violências

\footnotetext{
${ }^{5}$ Não seria possível fazer uma descrição pormenorizada de todos os relatos autobiográficos, dado os limites de extensão do texto. Assim, optamos por destacar elementos das histórias que se entrelaçam com os eixos das narrativas.
}

familiares e estruturais na subjetivação juvenil; e relações de violências de gênero e masculinidades presentes nas relações afetivas.

\section{Masculinidades e violências nas narrativas dos jovens participantes}

Em meio às narrativas que trouxeram as vivências dos jovens com os bailes funks, foi possível analisar as masculinidades, poder e violência.

Em um dos relatos, Pedro demonstra um pouco dessas experimentações ligadas aos bailes funks:

[Pesquisador] Como era essa sua relação com os bailes, atrás de mulheres, como eram os seus relacionamentos? [Pedro] Então, veio, no baile a gente, acho que todo mundo, pô, quer o quê? Quer se divertir. Briga em baile, já briguei algumas vezes, mas por motivos fútil, velho, tipo fora do padrão, mas a gente vai num baile procura se divertir, beber, conhecer pessoas diferentes, tanto faz homem ou mulher, a gente vai conhecer, né? Vamos tentar ter alguma coisa a mais com a garota, né? Já frequentei vários bailes, já frequentei vários lugares onde podia até ser perigoso no momento, veio, mas isso foi antes de eu ficar doente, aí depois que eu fiquei doente mudou tudo, veio.

A partir das experiências adquiridas com esses jovens, foi permitido compreender os bailes funks também como um espaço de socialização e subjetivação do jovem. Em contrapartida, essa relação mais estreita com as masculinidades, poder e violências leva-nos a pensar num modo de subjetivação da masculinidade hegemônica (Connell, 2013) conectada diretamente com a hierarquização 
entre gêneros, em que os bailes funks correspondem também a um lugar de afirmação e vivência dessa masculinidade. A hegemonia é também produzida nas relações entre esses jovens e as mulheres presentes nos bailes, conforme demonstra o relato de Júnior: "[Pesquisador] E o que você mais gostava lá no baile? [Júnior] Nossa, eu gostava da putaria. Eu ía mais por causa das muié [risos]. [Pesquisador] E o que rola no baile funk? [Júnior] Mais é droga. Mulherada, bebida”.

Esse panorama confirma um lugar determinado de ser homem que também se efetiva pela dominação sobre as mulheres, que, nesse caso, cumprem apenas a função de satisfazê-los sexualmente. O baile funk, segundo relato dos jovens, é um espaço onde eles buscam substâncias psicoativas como o álcool, que juntamente com as mulheres reforçam o lugar de ser "macho", conforme também aponta o trabalho de Zaluar (2000).

Nesse sentido, os bailes funks contribuem com a produção do modelo hegemônico de masculinidade, pois para se tornar homem de verdade o jovem deve desde cedo incorporar a guerra que garante a reprodução desses ideais e se baseia, em seus princípios, na diferenciação às mulheres e aos “não homens", conforme aponta Welzer-Lang (2001). Por isso, devem respeitar a hierarquia e se tornar produtores dessas mesmas premissas.

Cabe esclarecer que o objetivo não é condenar os bailes funks, que representa um elemento cultural e permite a construção de modos de socialização entre muitos jovens que diariamente são vítimas da dura realidade presente nas periferias brasileiras, mas sugerir algumas pistas que permitem enxergar como esses jovens significam esse momento de lazer quando inseridos num contexto permeado de violências, relações de poder e dominação e formas de expressão do ser homem. Os bailes funks, nesse sentido, podem ser analisados com mais profundidade, para que se possa avançar e compreender melhor suas relações com as masculinidades, poder e violência.

A difusão do movimento funk no Brasil, especialmente no Rio de Janeiro, conforme aponta Zaluar (2000), teve início na década de 1990 como uma alternativa de lazer até então inexistente para muitos jovens de classes populares, em sua maioria, pobres e negros.

Dayrell (2002) aponta que o funk expressa uma determinada maneira de se vivenciar essa condição juvenil, na qual os jovens experimentam trocas, sonhos e diversões. Essa condição muitas vezes era representada, segundo o mesmo autor, na imagem socialmente criada dos jovens pobres, constantemente associada à violência e à marginalidade, ou mesmo como potencialmente marginais. Desse modo, não cabe aqui estabelecer essa imagem naturalizada, mas sim descrever o modo como esses jovens experimentam e significam essa condição juvenil.

As violências familiares e estruturais experimentadas por esses jovens durante suas vidas emergiram durante as narrativas, configurando-se como outro aspecto importante no modo de significar essa experiência entendida como masculina.

Os operadores hierárquicos têm início na violência sofrida por muitos meninos, conforme afirma Welzer-Lang (2001), tornando 
o masculino inicialmente submisso a esse mesmo modelo para que depois alcance os privilégios. A guerra incorporada na educação de muitos meninos os preparam para as futuras guerras que enfrentarão mais adiante. Corroborando isso, Leandro iniciou a narrativa relatando as diversas agressões que sofreu ao longo da infância e da juventude, demonstrando o peso que isso teve em seu processo de socialização.

[Leandro] Quando eu era pequeno, meu padrasto batia muito em mim, batiam tanto que chegava a sair sangue. Com o final dos tempos, com 16, 17 anos, eu apanhava muito, daí eu falei assim: "ah, não quero mais apanhar, vou embora pro meu pai", e minha mãe não deixava ir embora. Daí, um certo dia, ele veio me bater, aí eu saí fora, fui pousar pra fora, daí rolou com outros moleques bagunça e... machucava muito ele batendo em mim e eu falei assim, se ele batesse mais uma vez em mim eu matava ele. Aí foi indo, depois ele não veio mais procurar eu, não vou mais na casa dele. [Pesquisador] Como que aconteciam esses episódios com o seu padrasto quando pequeno? [Leandro] Quando eu trabalhava, eu trabalhava, né, por exemplo, a gente trabalhava na chácara, aí eu apanhava pra puxar casquinha, massinha, tirá leite de vaca, essas coisas. E batia muito em mim e no meu irmão, aí teve um dia que eu falei assim: "vou embora e tal", aí eu saí pra rua e pousei uns quatro, três dias pra rua, aí eu fui pousar na casa da minha vó... daí fiquei pra rua, depois voltei pro meu pai, depois voltei, voltei agora, casei e ô pagando esse negócio aí do serviço comunitário.

Os episódios em que o jovem era agredido eram frequentes e exercidos por outro homem. Para ensinar a ser "homem de verdade", a violência é reforçada como dispositivo que aos poucos vai lapidando esse projeto hegemônico. O sentido atribuído a essa situação revelou a revolta do jovem que se revoltou contra o padrasto. Cabe-nos questionar se em uma vida marcada por tantas violências haveria outra possibilidade desse jovem se colocar diante das adversidades.

Além disso, Leandro afirma ter sofrido violência dos pais quando contou que cumpriria medida socioeducativa acusado de estupro. Com isso, nota-se que o diálogo se mostra ausente nas dificuldades familiares.

A violência se instaura como um elemento comum no cotidiano desse jovem, assim como as situações mais graves experimentadas no próprio bairro em que cresceu, tornando-se um fato corriqueiro, naturalizado e até esperado por quem morava em bairros pobres da periferia, como no relato de Pedro.

[Pedro] [...] na periferia onde eu morava, é um bairro com a margem de criminalidade bem alta, veio, roubo, morte. Nossa, desde quando eu moro naquela vilinha lá eu já vi umas 50 pessoas morrer lá, veio, tudo de forma brutalmente, sabe? [Pesquisador] E como você enxergava isso, como que era? [Pedro] Ah, pelo fato da gente morar num lugar onde o índice de criminalidade é bem alto, vamos dizer assim que aquilo fazia parte do nosso cotidiano, fazia parte. "Ah, fulano morreu. Ah, morreu de quê? Ah, mataram". Então, pra nóis era uma coisa normal, mesma coisa de chegá e falá assim: "ah, amanhã é quarta-feira". Então a gente não via problema nenhum de chegá e fala: “ah, fulano morreu. Ah, mataram fulano, arrancaram a cabeça de fulano". Pra nós não tinha constrangimento nenhum, porque pra nós era normal, onde toda semana três, quatro, que achava morto, 
apesar de que hoje tá mais calmo, mas antes era assim, acontecia briguinha à toa e já saía uma morte, e não era uma morte de tipo chegar e dar um tiro e morrer. Era morte chegava lá, abria o cara, arrancava a cabeça, picava... [Pesquisador] Era mais cruel, então... [Pedro] Até pelo fato de lá ser um bairro com a margem de criminalidade bem alta, o povo é tudo rebelde, veio. Qualquer coisinha tão brigando, tão matando, tão prejudicando um o outro.

O significado atribuído por Pedro é que a violência já era algo esperado naquela região, por estar localizada num bairro periférico. Desse modo, ela é um componente que perpassa muitos processos de subjetivação naquele ambiente, e que vai instaurá-la como forma de negociação de conflitos, pois a guerra que passa a ser incorporada nesses meninos não se demonstra apenas com marcas produzidas na própria pele, mas também com manifestações que são observadas durante a própria vida.

No decurso das narrativas, foi possível ainda analisar como os jovens constroem valores, práticas e significados, na perspectiva das relações de gênero, tomando por base suas relações afetivas, a partir de seus relatos autobiográficos, em que se buscou compreender quais masculinidades puderam ser notadas nesses relatos e se elas se vinculam a práticas cotidianas ou se mantêm como um ideal cultural por parte dos jovens.

O principal aspecto presente nos relatos dos jovens foi a relação com o sexo oposto. Em um dos casos, Pedro conta sobre sua relação com a esposa e a divisão das atividades consideradas do lar em seu cotidiano.
[Pesquisador] E como são as coisas na casa, divisão de tarefas? [Pedro] Ah, divisão de tarefas, vamos dizer assim, quando eu posso ajudo ela, eu cozinho, eu sei me virar, né? Aprendi isso com a minha mãe, aprendi a me virar. Então, às vezes ela tá cansada, porque ser dona de casa cansa, né? Aí não adianta falar, mas cansa, pô. Eu ajudo ela, de vez em quando faço uma janta, um almoço, ajudo a limpar a casa, não frequentemente, né, mas vamos dizer assim, umas duas vezes por semana eu ajudo ela a limpar a casa, limpar o quintal. Cuidar do cachorro eu que cuido, tenho um ciúmes dele, o cachorro é só meu... mas a divisão de tarefas dentro de casa é normal, é sem briga nenhuma, você faz isso, eu faço isso e pronto, não tem o que discutir. A gente se relaciona de uma forma assim: " $x$ " é " $x$ ", nem mais, nem menos, tipo assim, você faz a janta e eu lavo a louça da janta, ah, não que questionar, é isso e isso e pronto. Assim a gente evita briga e discussão, né? Então não tem o que questionar, é isso e isso e pronto e acabou. [Pedro] Hoje nóis vive bem, eu trabalho, ela não trabalha, mas que eu ganho dá para sustentar eu e ela, o que eu ganho mensalmente na faixa de 1.200, 1.300 pau por mês, sendo só eu e ela a gente não paga aluguel, a casa é própria, a gente vive bem, graças a deus. Bem tranquilos, sossegados, de forma digna e honesta.

Apesar de afirmar que auxilia a esposa nas atividades consideradas do lar, mantém a premissa de que mulher tem como principal função o cuidado do lar, enquanto o homem deve ser o provedor. Desse modo, os papéis esperados e desempenhados por cada um(a) se aproximam da afirmação de Connell (1995) de que muitos homens preferem manter boas relações com as esposas (e mães), inclusive auxiliando-as nos afazeres domésticos, mas se negam a questionar suas posições de privilégios. Com isso, há uma conexão com o projeto 
hegemônico de ser homem, embora não apresente, pelo menos num primeiro momento, elementos de ódio e violência.

Essa concepção traduz a ideia de que mesmo com o avanço que houve em alguns segmentos nas últimas décadas, as mulheres devem se restringir ao casamento, e mesmo que venham a trabalhar (por muitos não considerarem a atividade doméstica como trabalho) devem cuidar da casa e dos filhos(as). O papel de subordinação será mantido por meio da naturalização dos papéis designados para manter os padrões de masculinidades e feminilidades.

O relato de Júnior, no que tange ao envolvimento com mulheres, reforça a ideia que se tem a respeito das funções que devem ser desempenhadas por homens e mulheres.

[Pesquisador] Vocês faziam bastantes festinhas? [Júnior] Não, a gente ía pra [...] só, pra zona, ía lá bebia e cheirava. Fazia um monte de coisa, voltava no outro dia. [Pesquisador] E na zona, me conte mais sobre. [Júnior] Ah, tinha um monte de muié, pó, maconha, bebida. Aí, depois que eu saí da Febem, eu não fui mais pra lá. [Pesquisador] $O$ que você mais gostava na rua, o que era mais legal? [Júnior] Era as menina. [Pesquisador] A sua relação era mais ir lá... [Júnior] Minha relação era mais com o pó. [Pesquisador] Você pegava dinheiro pra sair com elas? Júnior] É, pra sair com as meninas. [Pesquisador] E nas "zonas", o que mais você encontrava? [Júnior] Tinha mulheres, outras pessoas. Nóis passava, sabe aquele trevo lá de [...], lá na saída da [...]? [Pesquisador] Sim. [Júnior] Não tem um monte de mulher bonita que fica lá? Não sei se tem ainda, nunca mais fui. Nóis passava em quebrada e pegava as menina e ia pros motel lá de [...], levava farinha, bebida. Ficava lá a noite inteira.
Nesse discurso é possível identificar valores na perspectiva de gênero que é inserido na lógica da masculinidade hegemônica, pois quando ele diz que "era só pra comê" e "saí fora", expressa que as mulheres estão lá apenas para satisfazer suas necessidades, reiterando certo desprezo e aversão pelo sexo oposto, conforme aponta Welzer-Lang (2001), quanto à premissa básica dos processos de socialização masculina para a produção do homem de verdade, que, de acordo com o mesmo autor, a obtenção de privilégios passa por essa diferenciação e desprezo pelas mulheres. Nessa perspectiva, esse processo relaciona o homem como um ser ativo e a mulher como passivo. É possível entender melhor essa premissa em uma das situações trazidas por Leandro, no que tange às relações entre os próprios homens.

[Pesquisador] E na rua, você via muita violência? [Leandro] Ah, via bastante. [Pesquisador] Você presenciava muita coisa então? [Leandro] Presenciava bastante. Já o vi o cara dar canivetada no outro. No baile funk, se o cara for pedófilo, os caras lincham mesmo. Não gosta dos caras que fuma pedra, não gosta. [Pesquisador] Não gosta por quê? [Leandro] Porque é discriminado. Os caras que fuma pedra são isolados. Coloca um cara que fuma pedra na cadeia pra vê. Os caras lincha ele. Pedófilo. Coloca um pedófilo na cadeia junto com os outros. Os caras lincha. Já era. O cara vira muié lá dos cara. [Pesquisador] Vira mulher? [Leandro] Vira mulher. [Pesquisador] Como assim, como é? [Leandro] Os cara regaça com ele. Ele gosta de come muié a força? Os cara regaça com ele lá dentro.

Cabe destacar que ao se referir sobre o termo pedófilo, caracterizado aqui como alguém que violenta sexualmente crianças e jovens do 
gênero masculino e feminino, o jovem aponta como o sujeito é discriminado e tratado como mulher pelos outros homens, ou seja, passa a assumir a posição passiva que é caracterizada como inferior e mais humilhante, demonstrando a relação de subordinação presente nas masculinidades (Connell, 1995). A masculinidade hegemônica, segundo Connell (1995), assimila a homossexualidade à feminilidade, entendida como uma violação da honra do homem para que assim se alcance maior reconhecimento e respeitabilidade social, pois, como nos lembra muito bem Sáez (2011), o homem é quem penetra, independentemente se forem mulheres ou mesmo outros homens. O importante nesse caso é ser ativo e impenetrável, pois o(a) penetrado(a), além de ser passivo e “não homem”, goza de menos prestígio e privilégios.

Nas relações afetivas entre os jovens do sexo oposto, essa situação também é vista, tanto nas casuais, expressadas anteriormente, como também em um relacionamento sério. Esse fato fica claro no relato de Márcio, quando questionado sobre suas relações amorosas.

[Pesquisador] E como eram suas relações amorosas? Já namorou? [Márcio] Já. [Pesquisador] E como era? Conte-me um pouquinho. [Márcio] Namorei duas vezes só. Uma delas fiquei uns três, quatro meses, e a outra vez eu fiquei dois anos e pouco, né? Aí eu fui preso. Aí, quando eu tava três meses lá dentro, a minha mãe me disse que ela tinha me traído. Aí na hora eu fiquei bravo, falei que ia matar ela, tudo, né? Aí nos três meses eu não tinha mudado de cabeça ainda, né? "Eu vou matar ela”, pensando em matar. Aí com o tempo, com uns nove meses de internação, comecei a mudar meu pensamento. Pensei: "fazer o quê? Se ela quis assim, deixa viver a vida dela". Aí eu vim pra cá e ela veio pra conversar comigo, mas na hora eu fiquei nervoso, né? Ela veio conversá comigo e eu, nervoso, saí andando. Conversei com ela esses dias. Aí depois no outro dia eu falei: ah, vou ter que conversar com ela, um dia ou outro vou ter que conversar com ela. Aí eu fui atrás dela na frente da escola pra conversá com ela. Aí ela falô que queria voltar comigo, e eu disse que não dava mais, falei pra ela que não ia aguentar olhar pra cara dela e pensar que ela já fez isso comigo um dia. Porque quando eu fiquei com ela, nunca fiz coisa errada com ela. Ela sabe disso, aí ela vai e faz uma palhaçada dessas comigo? [Pesquisador] E depois disso você ainda tem contato com ela? [Márcio] Ah, eu tenho amizade com ela ainda, mas assim... só amizade, né? Tem vez que eu tô conversando com ela e eu até paro para num xingar ela. Eu lembro das coisas que ela fez comigo e eu fico bravo.

Durante alguns meses passou pela cabeça de Márcio o desejo de cometer feminicídio devido a uma traição, que pode ser pensada como violação da honra do homem, pois a única resposta imediata é a violência de gênero. Essa ação pode ser justificada pelo discurso de que na traição feminina há uma intencionalidade, ao contrário da masculina, que é muitas vezes justificada com base na vontade sexual incontrolável, logo é vista como algo natural, segundo aponta Salem (2004) em sua pesquisa que analisou discursos sobre as sexualidades masculinas e femininas e a relação de gêneros de homens de classe popular no Rio de Janeiro. Nesse sentido, a masculinidade hegemônica também poderá se basear no ódio como resposta a fim de resgatar essa honra perdida por causa da traição sofrida. 
Segundo Márcio, depois de terminar o relacionamento com a namorada, ela tornou-se "biscate", pois passou a ficar com vários homens e com isso foi desqualificada e tratada como inferior para que assim seja mantido seu domínio e hegemonia. Há também nesse relato um indício de virilidade, pois o homem que fica com várias mulheres estaria apenas expressando sua condição viril, desempenhada por seu papel ativo, visto que as mulheres que ficam com vários homens são vistas como biscates, putas, etc. Essa situação pode ser vista pela diferenciação das mulheres por parte dos homens, com base no binômio vínculo/sexo, segundo aponta Salem (2004), conforme maior ou menor consideração e respeito por elas, de acordo com os comportamentos sexuais demonstrados. Nesse sentido, quanto mais parceiros elas tiverem, menos valorizadas serão pelos homens. Nesses termos, há uma classificação das mulheres baseada em marcos hierárquicos. Isso também foi notado na resposta de Júnior quando perguntado sobre a diferença entre as mulheres da rua ou das "zonas" e as mulheres que conviviam no seu próprio bairro: "Pesquisador] E qual a diferença entre as meninas daqui [do bairro] e de lá [das zonas]? [Júnior] Ah, de lá era só pra "comê", cheirar, beber e sair fora. E daqui não, nóis tem amizade e tudo. [Pesquisador] Só amizade? [Júnior] Ah, não, acontecia também. Acontece até hoje”.

As mulheres das "zonas", na concepção de Júnior, são apenas para “comê, cheirar, beber e sair fora", enquanto mantinha amizade com as mulheres do bairro, embora tenha afirmado que com elas aconteciam outras coisas também. Há uma diferenciação na forma de conceber as mulheres, sendo as primeiras descartáveis e usadas apenas para satisfazer suas necessidades de "macho", as quais se vinculam diretamente ao uso de drogas e bebidas alcoólicas, enquanto no segundo caso estabelecem um vínculo maior. Essa diferenciação é baseada no modo como o homem se satisfaz sexualmente, visto que com as prostituas há uma maior liberdade sexual que não implica no vínculo; ao contrário das meninas do próprio bairro, que requerem uma maior negociação em termos sexuais, e que reivindicam maior insistência por parte do jovem, que, em consequência, tende a concebêlas como mais valorizadas (Salem, 2004).

\section{Considerações Finais}

A partir do protagonismo de jovens do sexo masculino envolvidos com as violências, seja como vítimas, seja como autores, foi possível descrever valores, práticas e significados nas relações de gênero produzidas nas narrativas.

Nas produções discursivas que envolvem as masculinidades, deixamos o alerta para o modo como muitos meninos são subjetivados na busca dessa hegemonia, conforme aponta Connell (2013), pois são diversos os operadores hierárquicos que se manifestam durante seus processos de socialização, entre eles a aversão ao feminino, à homossexualidade e à aceitação de sofrimentos psíquicos e corporais para que se tornem homens mais honrados.

A produção discursiva que opera na relação entre masculinidade e violência determina, muitas vezes, os princípios que 
devem ser seguidos por muitos homens para atender ao projeto hegemônico, mesmo que isso signifique passar por sofrimentos e angústias, de modo a manter os privilégios numa ordem hierárquica de gênero. Esse controle dos discursos e práticas ainda é realizado por meio de doutrinas familiares, políticas, religiosas e filosóficas por meio de procedimentos de interdição que envolverá uma série de noções e princípios.

Pensamos que, para isso, as perspectivas críticas fundadas numa leitura queer (Córdoba, Sáez, Vidarte, 2005) são importantes aliadas no processo de desconstrução dos regimes binários e discursos que ainda enrijecem esses operadores hierárquicos com a promoção de sujeitos que escapam das normas esperadas, em relação às masculinidades que operam nessa lógica hegemônica dominante. A perspectiva queer, seguindo a proposta de contemplar aqueles e aquelas que se afastam das normas sexuais e identitárias, se aproxima de um rompimento importante que abre espaços para a pluralização das expressões das masculinidades. Segundo Garcia (2005), uma leitura queer remete a um ato de provocação, de reivindicação política.

Aproximando com a Psicologia, Peres (2013) propõe que esta rompa com esses sistemas binários e sedentários que ainda sustentam a lógica dominante de masculinidade e permita a manifestação de novos sujeitos (homens) emancipados, com destaque para sua posição política quanto ao exercício de direitos, resgatando assim possibilidades de outras expressões que também se afastem da visão reducionista, classificatória e diagnóstica que ainda acompanha muitas práticas psicológicas (Peres, 2013). Essas intervenções devem atingir instituições familiares, educacionais, assistenciais, da saúde com o propósito de desvincular discursos que tomam por base a violência para resolver conflitos, promovendo espaços onde os homens possam ressignificar suas experiências e a construção de "identidades múltiplas" (Penedo, 2008) que expressem novas masculinidades. Em paralelo, a capacitação de profissionais, entre os quais incluem os $\mathrm{da}$ própria Psicologia, numa perspectiva queer e de gênero, se faz necessária para a desconstrução de práticas e discursos homogêneas que concebem esses discursos como "naturais".

Por fim, pensamos que as problematizações oriundas da Psicologia, que promovem rompimentos diante da naturalização das masculinidades em relação à violência, são de extrema importância, ou seja, é mister rever teorias e formas de intervenção, levando em consideração aspectos múltiplos que têm papel no modo como a masculinidade hegemônica se produz.

Assim, faz-se necessário que a Psicologia se alie a perspectivas de gêneros em suas interseções com elementos étnicos raciais, de classe, sexuais e etários, por exemplo, para que seja possível o engendramento de outras discursividades, nas quais se espera que outros processos de subjetivação masculina de modo possam emergir, provocando deslocamentos das vinculações deterministas e lineares sobre as explicações acerca das violências cometidas por jovens. 


\section{Referências}

Adorno, S., Bordini, E. B. T., \& Lima, R. S. (1999). O adolescente e as mudanças na criminalidade urbana. Revista São Paulo em Perspectiva, 13(4). Recuperado de http:/ /dx.doi.org/10.1590/S010288391999000400007.

Aguayo, F., \& Nascimento, M. (2016). Dos décadas de estudios de hombres y masculinidades en América Latina: avances y desafíos. Revista Sexualidad, Saludy Soecidad, Rio de Janeiro, 22. Recuperado de http:/ /www.scielo.br/scielo.php?script $=\mathrm{s}$ ci_arttext\&pid=S198464872016000100207\&lng=es\&tlng=es.

Bakhtin, M. (1997). Estética da criação verbal. São Paulo: Martins Fontes.

Bakhtin, M. (2006). Marxismo e Filosofia da Linguagem (12a ed.). São Paulo: Hucitec.

Beiras, A., \& Nascimento, M. (2017). Homens e violência contra as mulheres: pesquisas e intervenções no contexto brasileiro. Rio de Janeiro: Instituto Noos.

Boris, G. D. J. B. (2002). Falas de homens: a construção da subjetividade masculina. São Paulo: Annablume.

Bruner, J. (1991). A construção narrativa da realidade. Critical Inquiry, 18(1), 1-21.

Burin, M. (2000). La construcción de la subjetividad masculina. In M. Burin \& I. Meler (Orgs.). Varones, Género y subjetividad masculina (pp. 83-104). Buenos Aires: Paidós.

Carvalho, I. C. M. (2003). Biografia, identidade narrativa: elementos para uma análise hermenêutica. Horizontes Antropológicos, Porto Alegre, 9(19), Recuperado de http://dx.doi.org/10.1590/S010471832003000100012 .

Coimbra, C., Bocco, F., \& Nascimento, M. L. (2005). Subvertendo o conceito de adolescência. Arquivos Brasileiros de Psicologia, 57(1), Recuperado de http://seer.psicologia.ufrj.br/index.php/ abp/article/view/6/10.

Connell, R. W. (2000b). Understanding Men: Gender Sociology and the New International Research on Masculinities. Paper Presented at the Clark Lecture, 19th September, 2000, Department of Sociology, University of Kansas. Retrieved from http://www.europrofem.org/contri/2_0 4_en/research-on-masculinities.pdf.

Connell, R. W. (1995). La organización social de la masculinidad. In C. Lomas (Comp.). ¿Todos los hombres son iguales? Identidades masculinas y cambios sociales. Barcelona: Paidós.

Connell, R. W., \& Messerschmidt, W. J. (2013). Masculinidade hegemônica: repensando o conceito. Revista Estudo Feministas, Florianópolis-SC, 1(21). Recuperado de http://dx.doi.org/10.1590/S0104026X2013000100014.

Dayrell, J. (2003). O jovem como sujeito social. Rev. Bras. Educ., Rio de Janeiro, 24. Recuperado de http://dx.doi.org/10.1590/S141324782003000300004.

Dayrell, J. (2002). O rap e o funk na socialização da juventude. Revista Educação e Pesquisa, São Paulo, 28(1). Recuperado de http://www.revistas.usp.br/ep/article/vi ew $/ 27880$.

Foucault, M. (2006). A ordem do discurso. São Paulo: Editora Loyola.

Flick, U. (2009). As análises de narrativa e a hermenêutica. In U. Flick. Introdução à Pesquisa Qualitativa (3a ed.). Porto Alegre: Artmed.

Flick, U. (2009). Narrativas. In U. Flick. Introdução à Pesquisa Qualitativa (3a ed.). Porto Alegre: Artmed.

Garcia, D. C. (2005). Teoría queer: reflexiones sobre sexo, sexualidad e identidad hacia una politización de la sexualidad. In D. Córdoba, J. Sáez \& P. Vidarte (Orgs.). Teoría Queer. Políticas Bolleras, maricas, trans, 
mestizas. Barcelona y Madrid: Editorial Egales.

Germano, I., \& Serpa, F. A. S. (2008). Narrativas autobiográficas de jovens em conflito com a lei. Revista Arquivos Brasileiros de Psicologia, Rio de Janeiro, 60(3). Recuperado de http:/ / seer.psicologia.ufrj.br/index.php/ $\mathrm{abp} /$ article/view/219.

Grossi, M. P. (2004). Masculinidades: uma revisão teórica. Revista Antropologia em Primeira Mão, Florianópolis. Recuperado de http:/ /apm.ufsc.br/titulospublicados/2004-2/.

Kimmel, M. (2001). Masculinidades globales: restauración y resistencia. In C. SánchezPalencia \& J. C. Hidalgo (Eds.). Masculino plural: construciones de la masculinidad. Lleida: Universitat de Lleida.

Lei n. 8.069, de 13 de Julho de 1990. (1990). Estatuto da Criança e do Adolescente. Recuperado de http://www.planalto.gov.br/ccivil_03/leis/L8069. htm.

Lei Federal n. 12.852, de 05 de Agosto de 2013. (2013). Estatuto da Juventude.

Recuperado de http://www.planalto.gov.br/ccivil_03/_a to2011-2014/2013/lei/112852.htm.

Lima, C. B. (2009). Jovens em conflito com a lei: liberdade assistida e vidas interrompidas. Londrina: Eduel.

Lyra, J., \& Medrado, B. (2008). Por uma matriz feminista de gênero para os estudos sobre homens e masculinidades. Revista Estudos Feministas, 16(3), 809-840 Recuperado de https://periodicos.ufsc.br/index.php/ref /article/view/S0104026X2008000300005.

Marcílio, M. L. (2006). História Social da Criança Abandonada (2a ed.). São Paulo: Hucitec.

Michaud, Y. (1989). A violência. São Paulo: Editora Ática.

Minayo, M. C. S. (1994). A violência sob a perspectiva da saúde pública. Caderno
Saúde Pública, Rio de Janeiro, 10(supl. 1),

7-18. Recuperado de

http://dx.doi.org/10.1590/S0102-

311X1994000500002.

Nascimento, M., Segundo, M., \& Barker, G. (2009). Homens, masculinidades e políticas públicas: aportes para equidade de gênero. Rio de Janeiro: Promundo.

Oliveira, C. S. (2005). Quem tem medo da violência juvenil?. In F. Hartmann \& n. C. F. Rosa JR. Violências e contemporaneidade. Porto Alegre: Artes e Ofícios.

Pais, J. M. (1990). A construção sociológica da juventude: alguns contributos. Análise Social, vol. XXV(105-106), 139-165.

Recuperado de http:/ / analisesocial.ics.ul.pt/documentos /1223033657F3sBS8rp1Yj72MI3.pdf.

Penedo, S. (2008). El laberinto queer: la identidad en tempos de neoliberalismo. Barcelona: Egales.

Peres, W. S. (2013). Psicologia e Políticas Queer. In F. S. T. Filho, W. S. Peres, C. A. Rondini \& L. L. de Souza (Orgs.). Queering: problematizaçôes e insurgências na Psicologia Contemporânea (pp.55-63). Cuiabá: Ed. UFMT.

Rogoff, B. (2005). A natureza cultural do desenvolvimento bumano. Porto Alegre: ArtMed.

Sáez, J. (2007). El contexto sociopolítico de surgimiento de la teoría queer. In D. Córdoba, J. Sáez \& P. Vidarte. Teoría queer: politicas bolleras, maricas, trans, mestizas. Madrid: Ed. Egales.

Salem, T. (2004). "Homem... já viu; né?”: representações sobre sexualidade e gênero entre homens de classe popular. In M. L. Heilborn, M. (Org.). Família e sexualidade. Rio de Janeiro: Editora FGV.

Seidler, V. J. (2000). La sinrazón de la masculinidad: masculinidad y teoría social. Barcelona: Paidós.

Seidler, V. J. (2006). Introducción: Varones jóvenes y masculinidades. In V. J. Seidler. 
Masculinidades: culturas globales y vidas intimas. Barcelona: Montesinos.

Souza, E. R. (2005). Masculinidade e violência no Brasil: contribuições para a reflexão no campo da saúde. Ciência \& Saúde Coletiva, Rio de Janeiro, 10(1), 59-70. Recuperado de http:/ /dx.doi.org/10.1590/S141381232005000100012 .

Volpi, M. (2010). O adolescente e o ato infracional (8a ed.). São Paulo: Cortez.

Welzer-Lang, D. (2004). Os homens e o masculino numa perspectiva de relações sociais de sexo. In M. Schpun (Org.). Masculinidades (pp. 107-128). São Paulo/Sta. Cruz do Sul: Boitempo/Unisc.

Welzer-Lang, D. (2001). A construção do masculino: dominação das mulheres e homofobia. Revista Estudos Feministas, Florianópolis, 9(2). Recuperado de https://periodicos.ufsc.br/index.php/ref /article/view/S0104 026X2001000200008/8853.

Zaluar, A. (2002). A guerra sem fim em alguns bairros do Rio de Janeiro. Ciência e Cultura., São Paulo, 54(1). Recuperado de http://cienciaecultura.bvs.br/scielo.php? pid $=$ S0009-

67252002000100019\&script=sci_arttext.

Recebido em: $1^{\circ} / 4 / 2018$

Aprovado em 28/8/2019 